\title{
Improved rapeseed oil extraction yield and quality via cold separation of ethanol miscella
}

\author{
Morgane Citeau ${ }^{1, *}$, Sara Albe Slabi ${ }^{2}$, Florent Joffre ${ }^{3}$ and Patrick Carré ${ }^{1}$ \\ ${ }^{1}$ OLEAD, 11 rue Gaspard Monge, 33600 Pessac, France \\ ${ }^{2}$ University of Lorraine, LRGP, CNRS-UMR-7274, Plateforme SVS, Vandoeuvre-Lès-Nancy, France \\ ${ }^{3}$ ITERG, 11 rue Gaspard Monge, 33610 Canéjan, France
}

Received 12 November 2017 - Accepted 13 February 2018

\begin{abstract}
In the extraction of vegetable oils, the idea of using ethanol as a solvent, allowing solvent recycling without distillation, can be attested as early as 1948 (Beckel), yet it is now seldom envisaged. The development of organic farming and a growing demand for a more natural diet prompted us to revisit this approach, which takes advantage of the relatively low affinity of ethanol for lipids to produce pure crude oils and meal with higher protein content. This method is based on the change of oil solubility in ethanol with temperature. Rapeseed oil extraction was carried out by hot pressurized ethanol (subcritical extraction condition). Oil was then recovered by cooling the miscella and demixing of two phases, an oil-rich phase and a solvent-rich phase. This study, after verifying the kinetics of extraction, focused on the optimization of the demixing temperature based on the amount and quality of recovered oil. The results show that ethanol extraction followed by cold demixing of the miscella makes it possible to obtain a high quality oil, free of free fatty acids and phospholipids.
\end{abstract}

Keywords: alternative solvent / ethanol / rapeseed / extraction / non-distillation separation

\begin{abstract}
Résumé - Amélioration du rendement d'extraction et de la qualité de l'huile de colza par séparation à froid du miscella éthanol. Si dans le domaine de l'extraction des huiles végétales, l'idée d'utiliser l'éthanol comme solvant permettant un recyclage du solvant sans distillation peut être attestée dès 1948 (Beckel), elle n'est plus que rarement abordée de nos jours. Le développement de l'agriculture biologique et une demande grandissante pour une alimentation plus naturelle nous incitent à revisiter cette approche qui tourne en avantage la relativement faible affinité de l'éthanol pour les lipides pour produire des huiles brutes épurées et des tourteaux concentrés en protéines. Cette méthode est basée sur le changement de solubilité de l'huile dans l'éthanol avec la température. L'extraction de l'huile de colza a été réalisée à l'aide d'éthanol liquide chaud sous pression (condition d'extraction subcritique). L'huile est ensuite séparée du miscella par démixtion à basse température. Cette étude, après avoir vérifié les cinétiques d'extraction, a porté sur l'optimisation de la température de démixtion, basée sur la quantité et la qualité de l'huile récupérée. Les résultats montrent que l'extraction éthanol suivie par la démixtion à basse temperature du miscella permet d'obtenir une qualité de l'huile élevée, notamment exempte d'acides gras libres et de phospholipides.
\end{abstract}

Mots clés : solvant alternatif / éthanol / colza / séparation sans distillation

\section{Introduction}

The currently used oilseed crushing process includes a solvent extraction step, which removes the oil remaining in the press cake. Hexane is commonly used for this extraction, in

\footnotetext{
*Correspondence: m.citeau@olead.fr
}

particular to produce rapeseed oil. Although extraction by hexane is technically and economically efficient, and the process is well optimized in the crushing industry, its use is problematic. Hexane is a threat to workers' safety and health, and to the environment: it is a volatile organic compound derived from petroleum and classified as toxic, flammable and explosive. Research is in progress on the development of alternative processes to replace hexane and enhance the quality and value of oil and meal. 
Various solvents, mainly from renewable resources, have been tested as possible hexane substitutes (Fine et al., 2013; Sawada et al., 2014; Sicaire et al., 2015a). Ethanol seems a promising alternative solvent. Compared with other "green" solvents, it is less toxic, already authorized for food extraction by the European Directive 2009/32/EC, readily available and bio-based (Perrier et al., 2017). Furthermore, ethanol solubilizes some non-lipid components such as sugars, and to a lesser extent phenolic compounds, glucosinolates and phytates, which are considered as anti-nutritional components of rapeseed (Berot and Briffaud, 1983; Kozlowska et al., 1991; Fauduet et al., 1995; Zhang and Liu, 2007). Ethanol extraction thus concentrates proteins in the meal and detoxifies it.

However, some constraints have so far limited the industrialization of ethanol extraction: ethanol has a low capacity to solubilize the oil at conventional extraction temperatures, a low selectivity for oil, and a high regeneration cost compared with hexane. Oil extraction efficiency with ethanol can be increased by raising the extraction temperature and/or lowering water content in the ethanol (Rittner, 1992; Sawada et al., 2014; Toda et al., 2016). In particular, Rao and Arnold (1956) demonstrated that rapeseed oil solubility in ethanol-water azeotrope increased from $<2 \mathrm{wt} . \%$ at room temperature to $11.3 \mathrm{wt} . \%$ at $90^{\circ} \mathrm{C}$. However, oil solubility in ethanol-water mixtures falls steeply when the water content in the mixture reaches 6 wt.\% (Rodrigues and Oliveira, 2010; Sawada et al., 2014).

In experiments on rice bran pellets, Bessa et al. (2017) confirmed the feasibility of oil extraction by a multistage countercurrent process using hot pressurized ethanol. They demonstrated that the efficiency of extraction was improved by proceeding at a temperature above the boiling point $\left(78.3^{\circ} \mathrm{C}\right.$ at atmospheric pressure): better extraction kinetics and higher oil yield were obtained at $100^{\circ} \mathrm{C}$ at a pressure of $410 \mathrm{kPa}$. Mathematical simulation estimated a minimal solvent/solid ratio of $1.9 \mathrm{wt} / \mathrm{wt}$ for complete oil extraction with $100 \%$ ethanol in a five-stage countercurrent extractor. In comparison, a minimal solvent/solid ratio of $0.8 \mathrm{wt} / \mathrm{wt}$ was required for conventional extraction with hexane (Bessa et al., 2017).

The problem remains that ethanol is less volatile than hexane: more energy is required to remove ethanol from extracted meal and miscella by heating and evaporation. Ethanol extraction where a miscella is evaporated compares poorly with hexane extraction for oil quality and energy cost. Besides the cost drawback, distillation of ethanol miscella leads to a mixture of lipids, carbohydrates and phenol compounds that is difficult to refine. A possible solution to these problems is to use an alternative method of solvent recovery from miscella, namely: "Hot Ethanol extraction followed by Cooling Separation of the miscella (HECS)". This method is based on the change of oil solubility with temperature. The concentrated miscella is cooled in a heat exchanger where the heat is transferred to the solvent flowing towards the extractor. The concentrated miscella is then transferred to a decanter where it separates into oil- and solvent-rich phases. The decantation can be carried out in a static or a centrifugal device. This method has been tested by Beckel et al. (1948a) on soybean, by Hron and Koltun (1984) on cottonseed, and by Mabona et al. (2014) on spent coffee grounds. Beckel et al. (1948a) demonstrated that ethanol separated by miscella cooling could be re-used directly as an extraction solvent at least 75 times without rectification. The energy requirement of this process was estimated at $3 / 4$ of that for classical hexane extraction (Beckel et al., 1948a). However, Mabona et al. (2014) demonstrated that a nonnegligible quantity of extracted oil could be lost to the removed ethanol phase (16-43\% of the oil extracted from spent coffee grounds depending on operating conditions). These losses can nevertheless be mitigated by decreasing the solvent/solid ratio (from 7.5 to $5 \mathrm{wt} / \mathrm{wt}$ ) and the demixing temperature (from 45 to $15^{\circ} \mathrm{C}$ ). Hence efficiency (in terms of extraction kinetics, oil yield and purity) and economic feasibility (energy consumption, oil loss in solvent rich-phase) of the HECS method depends on the product type, solvent composition and operational parameters (mainly demixing temperature).

The aim of this work was to test the cooling separation method for recovery of rapeseed oil extracted by the HECS method, and to study the influence of the separation temperature $\left(+13,+5\right.$, and $\left.-20^{\circ} \mathrm{C}\right)$ on the quantity and composition of obtained oil- and solvent-rich phases.

\section{Materials and methods}

The full experimental procedure is presented in Figure 1.

\subsection{Seed preparation for oil extraction}

Rapeseeds were dehulled to produce a pure kernel fraction, which was flaked to break the seed cellular structure, reduce particle size, and facilitate oil extraction. The flakes were dried in an oven at $70^{\circ} \mathrm{C}$ to a residual moisture content of $3 \mathrm{wt} . \%$. The drying was required to prevent water transfer from solid to solvent during extraction (Abraham et al., 1993). Initial oil content of dried kernel was $52.5 \mathrm{wt} . \%$ according to the NF v03-908 method.

\subsection{Oil extraction}

Dried flaked kernels were extracted with ethanol-water azeotrope (95.6 wt.\% ethanol and $4.4 \mathrm{wt} . \%$ of water) at $95^{\circ} \mathrm{C}$ and a pressure of $340-360 \mathrm{kPa}$ throughout.

The extraction experiments were carried out in an agitated Nutsche filter (POPE Scientific Inc., USA) of total capacity $2.78 \mathrm{~L}$, equipped with a double jacket for temperature control, and an agitator for mechanical stirring. A stainless steel $20 \mu \mathrm{m}$ mesh (5 layers) on the bottom of the filter separated the solid from the miscella after the desired extraction time. The solidsolvent mixture was stirred during the extraction at $42 \mathrm{rpm}$ to ensure product homogeneity.

Two types of experiment were performed:

- analysis of extraction kinetics and optimization of extraction time;

- oil recovery by cooling of miscella and analysis of cooling temperature of the recovered oil composition.

\subsubsection{Study of oil extraction kinetics}

The experiments on oil extraction kinetics were performed by immersing $300 \mathrm{~g}$ of dried flaked kernels in $1500 \mathrm{~g}$ of the 


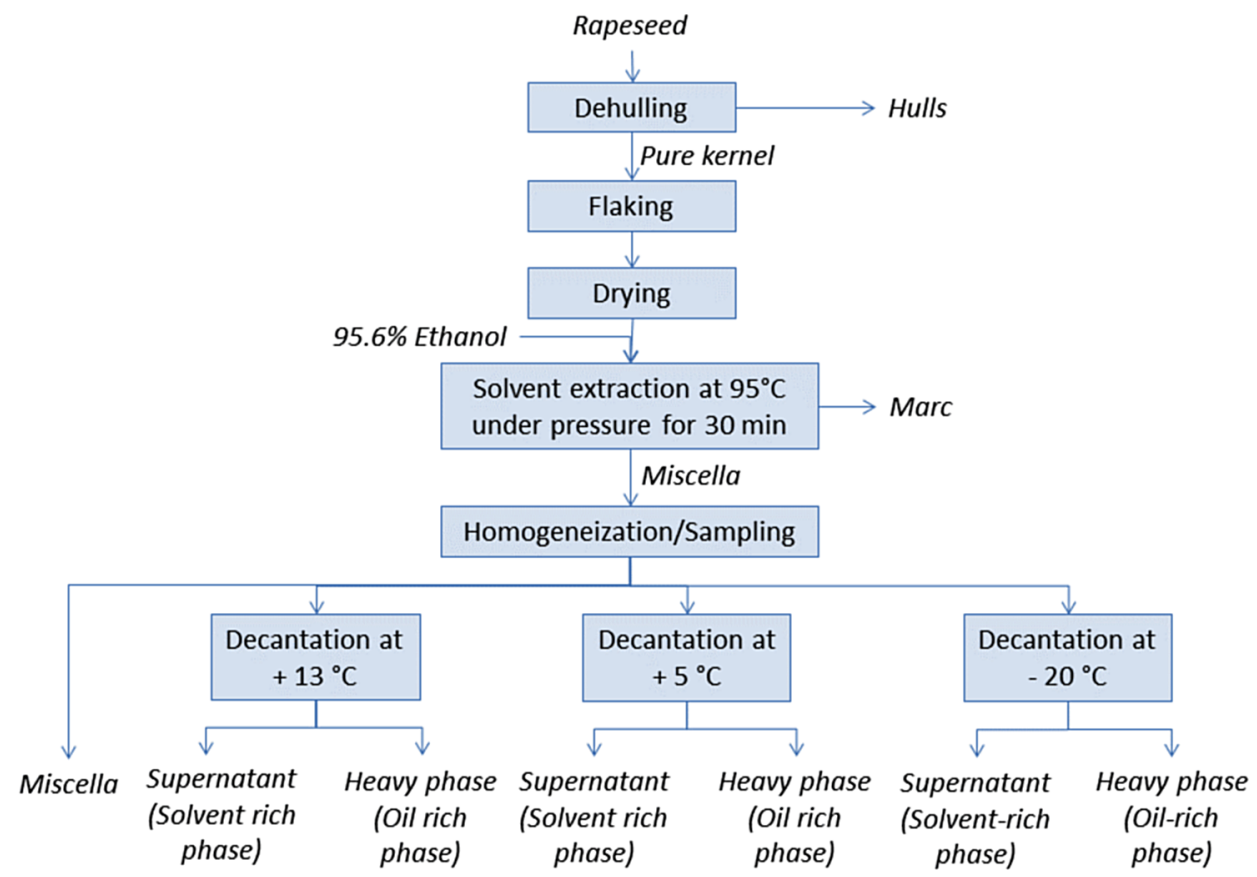

Fig. 1. Extraction procedure.

solvent, pre-heated to $95^{\circ} \mathrm{C}$. Miscella samples (7-10 g) were taken regularly during the extraction. The total extraction time was $1 \mathrm{~h}$. The samples were desolventized in an oven $\left(103.5^{\circ} \mathrm{C}\right.$, $13 \mathrm{~h})$ to measure the dry matter content. Some miscella samples were used for the analysis of the lipids and non-lipid dry matter content by liquid-liquid extraction in hexane then water (1: $1: 0.4 \mathrm{wt} / \mathrm{wt}$ ).

\subsubsection{Miscella preparation for cooling separation}

The experiments on cooling separation were performed by immersing $250 \mathrm{~g}$ of kernels in $1250 \mathrm{~g}$ of the solvent, pre-heated to $95^{\circ} \mathrm{C}$. The extraction time was set at $30 \mathrm{~min}$, which was sufficient for complete oil extraction, according to the preliminary extraction kinetics analysis. After the extraction, the miscella was separated from the solid by filtration and collected in a warmed beaker. The recovered miscella was promptly homogenized using a high shear mixer L5M-A (Silverson, USA), and divided into four parts (250-300 g of miscella collected in closed bottles) to undergo cooling separation (Fig. 1).

\subsection{Cooling separation of miscella}

Three samples of miscella were stored for $18 \mathrm{~h}$ at $+13{ }^{\circ} \mathrm{C}$, $+5^{\circ} \mathrm{C}$ or $-20^{\circ} \mathrm{C}$. Owing to the temperature decrease during storage, the miscella separated into two liquid phases: a solvent-rich phase (supernatant) and an oil-rich phase (heavy phase). Observations showed that the storage time was sufficient for complete demixing at every temperature studied. The supernatant and the heavy phases were quantitatively separated by decantation (at the storage temperature) and analysed.

\subsection{Analysis}

\subsubsection{Oil extraction yield}

The total oil extraction yield $\left(Y_{\text {ext }}^{t}\right)$ was calculated considering the oil content in miscella samples in relation to the initial oil content in kernels:

$$
Y_{\mathrm{ext}}^{t}=\frac{m^{S} C_{\mathrm{oil}}^{M}}{\left(1-C_{\mathrm{oil}}^{M}\right) m^{F} C_{\mathrm{oil}}^{F}},
$$

where $m^{S}$ and $m^{F}$ are the weights of solvent and of flakes used for extraction, respectively, and $C_{\text {oil }}^{M}$ and $C_{\text {oil }}^{F}$ are the weight fractions of oil in the miscella sample and initial flakes, respectively.

\subsubsection{Analysis of extraction kinetics}

The analysis of oil extraction kinetics was done as described in detail by Allaf et al. (2014) and Sicaire et al. (2015b). In brief, the analysis was based on the presentation of the flakes-solvent mixture as a polydisperse suspension with a known particle size distribution, and application of Crank's equation for diffusion from a monodisperse suspension of spherical particles (Crank, 1975) to each class of particle size $j$. Only the first term of the complete Crank's diffusion equation was used (as it was previously done by Allaf et al. (2014) and Sicaire et al. (2015b)), since superior terms had only insignificant impact on the result of analysis at the studied extraction time range, $t>2 \mathrm{~min}$. The total oil extraction yield $Y_{m o d}^{t}$ was calculated as a sum of the extraction yield from each particle class $j$ :

$$
Y_{\text {mod }}^{t}=\sum_{j} F_{j} \times\left(1-\exp \left(-\pi^{2} \times D_{\mathrm{eff}} \times t\right) / r_{j}^{2}\right),
$$




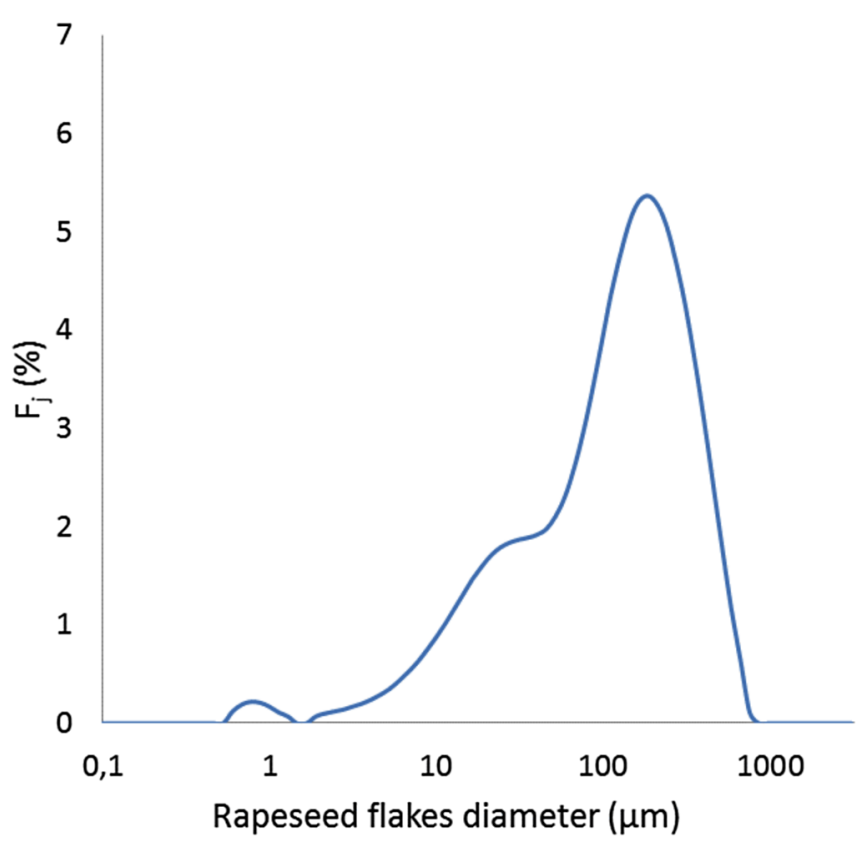

Fig. 2. Particle size distribution of rapeseed flakes $\left(F_{j}\right.$-proportion of particles).

where $F_{j}$ is the fraction of particles with the equivalent sphere radius $r_{j}$ in the sample, $D_{\text {eff }}$ is the effective diffusivity, and $t$ is the extraction time. The value of $D_{\text {eff }}$ was calculated by least square fitting of the experimentally measured dependency of $Y_{\text {ext }}^{t}$ on the extraction time with the help of Equation (2). The dependency $F_{j}\left(r_{j}\right)$ (i.e., the particle size distribution function), required for the calculations, was measured using a laser particle size analyser (Malvern Instruments) (Fig. 2).

\subsubsection{Analytical measurements}

All samples (miscella, supernatant and heavy phase) were first desolventized by freeze-drying COMOS (Cryotec, France). The solvent content in the samples was calculated from the weight loss after freeze-drying. The lipids and nonlipid dry matter content in the obtained crude oil (without solvent) were measured by the liquid-liquid extraction method of Folch (Folch et al., 1957). The following analyses were carried out on the extracted lipids: glyceride composition (adapted from IUPAC 6.002), tocopherol content (ISO 9936), fatty acid profile (ISO 12966-2 and 4) and phosphorus content (ISO 10540-1). A multiplication factor of 26.5 was used to convert the percentage of total phosphorus to the phospholipid content. The factor value of 26.5 is conventionally used for this conversion (Mordret, 1992). It is the ratio of the average molar mass of phospholipids and phosphorus.

\subsubsection{Decanted yield of components}

Decanted yield of a component $Y_{\mathrm{dec}}^{k}$ corresponded to the quantity of this component in the heavy phase after the decantation compared with its total quantity in the extracted miscella (before the cooling separation):

$$
Y_{\mathrm{dec}}^{k}=\frac{m_{k}^{\mathrm{HP}} C_{k}^{\mathrm{HP}}}{m_{k}^{\mathrm{HP}} C_{k}^{\mathrm{HP}}+m_{k}^{\mathrm{SN}} C_{k}^{\mathrm{SN}}},
$$

where $m_{k}^{\mathrm{HP}}$ and $m_{k}^{\mathrm{SN}}$ are the weights of the component $k$ (oil, non-lipid dry matter, triglycerides, diglycerides, monoglycerides, free fatty acids, tocopherols, phospholipids, sterols) in the heavy phase (HP) and in supernatant (SN), respectively, and $C_{k}^{\mathrm{HP}}$ and $C_{k}^{\mathrm{SN}}$ are the weight fractions of this component in the heavy phase or supernatant.

\subsubsection{Removal yield of components}

Removal yield of a component $Y_{\text {rem }}^{k}$ was the quantity of this component removed from the heavy phase after the decantation compared with its total quantity in the extracted miscella (before the cooling separation):

$$
Y_{\mathrm{rem}}^{k}=1-Y_{\mathrm{dec}}^{k}
$$

\subsection{Statistical analysis}

All experiments and analyses were repeated three times. To evaluate the effect of cooling temperature on final composition of various phases, data was submitted to analysis of variance (ANOVA, in Excel) with $p<0.05$.

\section{Results and discussion}

\subsection{Extraction kinetics}

Figure 3 presents the data on oil extraction kinetics. The use of hot pressurized ethanol-water azeotrope resulted in fast and efficient removal of oil from kernels: practically complete oil extraction yield was reached in only $10 \mathrm{~min}$ of the process (Fig. 3). Owing to the high extraction temperature $\left(95^{\circ} \mathrm{C}\right)$, the observed oil content in miscella (up to $9.7 \pm 0.4 \mathrm{~g} / 100 \mathrm{~g}$ of miscella) was substantially higher than the miscibility threshold of vegetable oil in ethanol-water azeotrope at room temperature $(<2 \mathrm{~g} / 100 \mathrm{~g}$ of miscella according to Rao and Arnold, 1956). The weight fraction of lipids in the total quantity of dry matter extracted to miscella was $88.6 \pm 1.9 \%$

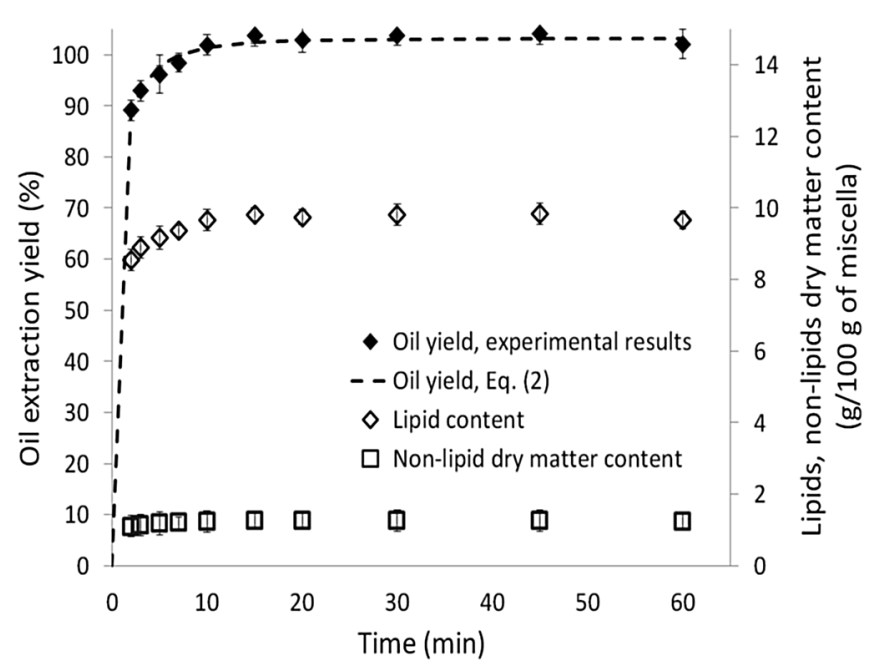

Fig. 3. Kinetics of the rapeseed oil extraction using hot pressurized ethanol $\left(95.6 \%\right.$ ethanol and $4.4 \%$ water; $\left.95^{\circ} \mathrm{C}\right)$. The error bars represent the standard deviation. 
and did not significantly change during the extraction process $(p>0.05)$.

The measured oil extraction yield (filled symbols in Fig. 3) was satisfactorily fitted by Equation (2) (dashed curve) with the coefficient of determination $R^{2}=0.958$. The value of the effective diffusion coefficient estimated by this fitting was $D_{\text {eff }}=(1.86 \pm 0.02) \times 10^{-11} \mathrm{~m}^{2} / \mathrm{s}$. In comparison, Sicaire et al. (2015b) found a diffusion coefficient of $0.34 \times 10^{-11} \mathrm{~m}^{2} / \mathrm{s}$ for rapeseed flakes in a conventional hexane extraction process (for a temperature of $55^{\circ} \mathrm{C}$ ). The value of the effective diffusion coefficient characterizes the extraction kinetics for a given temperature and solvent type independently of the particle size and solvent/solid ratio. Kinetics of rapeseed flakes extraction in hot ethanol-water azeotrope $\left(95^{\circ} \mathrm{C}\right)$ thus outperformed that in the traditional extraction process (hexane, $\left.55^{\circ} \mathrm{C}\right)$.

\subsection{Cooling separation}

\subsubsection{Extraction step}

The extraction was performed for $30 \mathrm{~min}$, which was sufficient for complete oil recovery from the flakes (Fig. 3). The recovered miscella contained $8.8 \pm 0.5 \mathrm{~g}$ of oil, $1.5 \pm 0.02 \mathrm{~g}$ of non-lipid dry matter and $89.7 \pm 0.4 \mathrm{~g}$ of solvent per $100 \mathrm{~g}$ of miscella. These results were in line with the results of the kinetics study. Consistent with previously published data, ethanol extracted some non-lipid dry matter (sugars, phenolic components, minerals and some proteins) (Berot and Briffaud, 1983; Kozlowska et al., 1991; Zhang and Liu, 2007). These components were solubilized in miscella resulting in meal detoxification: from the material balance, $14.2 \pm 0.2 \mathrm{wt} . \%$ of non-lipid dry matter was extracted from kernels.

\subsubsection{Decantation step}

\subsubsection{Oil distribution between two phases and crude oil quality}

Figure 4 presents the mass distribution of two separated phases after the cooling of miscella to different temperatures. The oil-rich phase (heavy phase) represented 9-10 wt.\% of the total quantity of miscella.

Table 1 presents the composition of initial miscella and two phases separated by cooling at different temperatures. Before the cooling separation, miscella contained about $90 \mathrm{~g}$ of solvent and $10 \mathrm{~g}$ of dry matter per $100 \mathrm{~g}$ of miscella, and the non-lipid dry matter (i.e., impurities) represented around

\section{Supernatant Heavy phase}

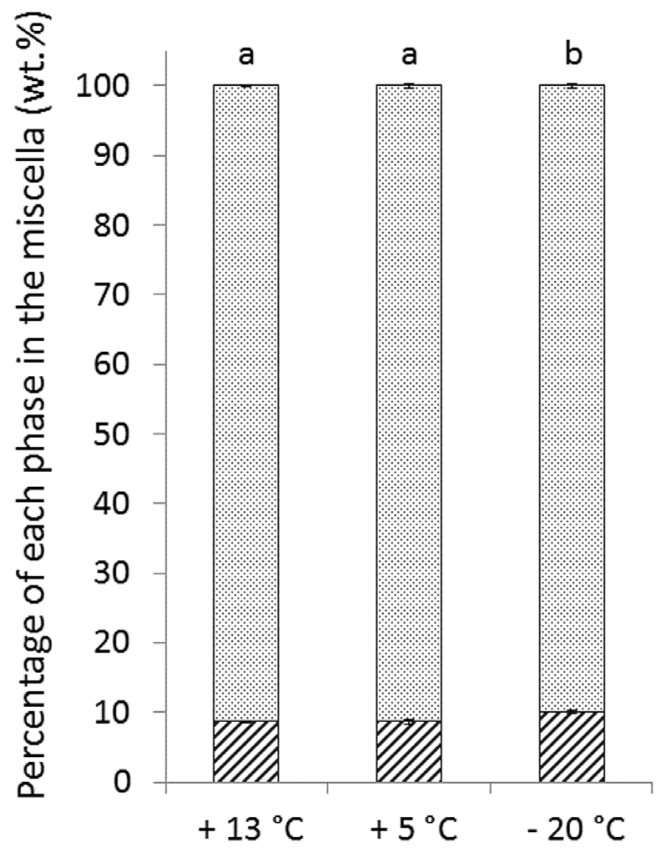

Fig. 4. Influence of the cooling temperature on the mass distribution between the supernatant and heavy phases (' $a, b$ ' indicate a difference at $p<0.05)$.

14 wt. $\%$ of the dry matter. The cooling separation resulted in significant component distribution between new phases: the supernatant contained most of the solvent and non-lipids of the miscella, while the heavy phase contained most of the extracted lipids, a small quantity of solvent and traces of nonlipid impurities (Tab. 1). After the cooling separation, the decanted oil of the heavy phase contained much less non-lipids (around 2-3 wt.\% of the crude oil, depending on the cooling temperature), while $97-98$ wt.\% of the dry matter was lipids. Crude oil purity in the heavy phase was therefore significantly higher than in the miscella, the non-lipid dry matter was retained in the solvent-rich phase: separation by cooling thus resulted in significant spontaneous purification of extracted crude oil.

The total quantity of dry matter remaining in the supernatant was low (2.5-3.2 g/100 g of supernatant depending

Table 1. Composition of the initial miscella and two phases separated at three cooling temperatures (DM-dry matter).

\begin{tabular}{|c|c|c|c|c|c|c|c|}
\hline \multirow{2}{*}{$\begin{array}{l}\text { Process step } \\
\text { Separation temperature } \\
\text { Sample }\end{array}$} & \multirow{2}{*}{$\frac{\frac{\text { Extraction }}{-}}{\text { Miscella }}$} & \multicolumn{6}{|c|}{ Cooling separation } \\
\hline & & Supernatant & Heavy phase & Supernatant & Heavy phase & Supernatant & Heavy phase \\
\hline Non-lipid DM ( $g / 100 \mathrm{~g}$ of phase) & $1.5 \pm 0.02$ & $1.7^{\mathrm{c}} \pm 0.1$ & $1.1^{\mathrm{a}} \pm 0.1$ & $1.6^{\mathrm{c}} \pm 0.1$ & $1.8^{\mathrm{b}} \pm 0.1$ & $1.6^{\mathrm{c}} \pm 0.1$ & $2.3^{\mathrm{b}} \pm 0.2$ \\
\hline Solvent $(\mathrm{g} / 100 \mathrm{~g}$ of phase $)$ & $89.7 \pm 0.4$ & $96.8^{\mathrm{c}} \pm 0.1$ & $10.5^{\mathrm{a}} \pm 0.1$ & $97.2^{\mathrm{d}} \pm 0.1$ & $10.5^{\mathrm{ab}} \pm 0.7$ & $97.5^{\mathrm{d}} \pm 0.1$ & $16.2^{\mathrm{b}} \pm 1.9$ \\
\hline
\end{tabular}

\pm standard deviation; ' $\mathrm{a}, \mathrm{b}, \mathrm{c}, \mathrm{d}, \mathrm{e}$ ' indicate a difference at $p<0.05$. 
on the cooling temperature). This supports the suggestion of Beckel et al. (1948a, b) that the supernatant could be reused as a solvent for extraction without complete solvent distillation.

Figure 5 presents the quantity of lipids, non-lipid compounds and solvent recovered in the heavy phase after the cooling and decantation (compared with the total quantity of respective components in extracted miscella; Eq. (3)). The percentage of recovered lipids and non-lipid compounds in the heavy phase increased significantly with decreasing temperature $(p>0.05)$. In parallel, the solvent-rich phase became poorer in oil as the temperature decreased (Tab. 1). The cooling temperature can therefore be selected to reduce the oil losses in the supernatant or increase the crude oil purity in the heavy phase.

The heavy phase contained $10-16 \mathrm{~g} / 100 \mathrm{~g}$ of solvent, while the initial miscella contained $90 \mathrm{~g} / 100 \mathrm{~g}$ of solvent. The solvent remaining in the heavy phase (and so requiring distillation for its recovery) represented only $1.0-1.9 \%$ of the total solvent quantity used for extraction (Fig. 5). Thus the application of the cooling separation method reduced to $9-10 \%$ the quantity of product needing to undergo thermal purification (only the heavy phase instead of the whole miscella), and significantly decreased the energy required for the solvent evaporation of the oil. In comparison, concentration of hexane in miscella obtained in a traditional multistage countercurrent extraction is about 75\% (Carré, 2012). The energy required for solvent evaporation from both miscellas (hexane-containing miscella after conventional solvent extraction and ethanol-containing heavy phase in this alternative process) can be compared using (i) the latent heats of vaporization of corresponding solvents and (ii) the solvent/oil mass ratio in miscella:

(i) $\Delta H_{E t O H}=977 \mathrm{~kJ} / \mathrm{kg}$ for ethanol-water azeotrope with $95.6 \mathrm{wt} . \%$ alcohol and $\Delta H_{H e x}=335 \mathrm{~kJ} / \mathrm{kg}$ for hexane, at corresponding boiling temperatures (NIST);

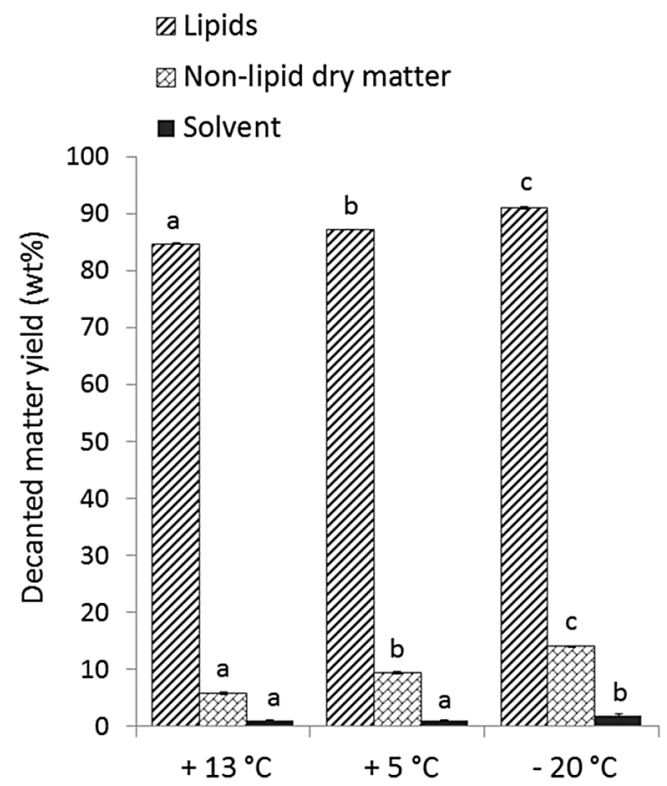

Fig. 5. Influence of the cooling temperature on oil, non-lipid dry matter and solvent recovery in the heavy phase compared with the extracted matter (Eq. (3)) ('a, b, c' indicate a difference at $p<0.05$ ). (ii) $m_{E T O H} / m_{O i l}=0.12$ in the heavy phase at a cooling temperature of $5^{\circ} \mathrm{C}$ and $m_{\text {Hexane }} / m_{m_{\text {Oil }}}=3$ in hexane-based miscella.

The comparison of energies required to evaporate ethanol at $95.6 \mathrm{wt} . \%$ and hexane in order to recover the same oil quantity can be determined using the following equation:

$$
\frac{Q_{E t O H}}{Q_{H e x}}=\frac{m_{E t O H} \times \Delta H_{E t O H}}{m_{H e x} \times \Delta H_{H e x}}=0.12,
$$

where $\quad Q_{E t O H}=\left(\frac{m_{E t O H}}{m_{\text {oil }}} \times \Delta H_{E t O H}\right) \quad$ and $Q_{H e x}=\left(\frac{m_{H e x}}{m_{\text {oil }}} \times \Delta H_{H e x}\right)$ are evaporation energy of ethanol and hexane, respectively, expressed on mass of crude oil content in the miscella basis (kJ/kg of oil), $m_{E t O H}, m_{H e x}$ and $m_{\text {oil }}$ are mass of ethanol, hexane and crude oil in miscella, respectively $(\mathrm{kg})$ and $\Delta H_{E t O H}$ and $\Delta H_{H e x}$ are latent heats of vaporization of ethanol $95.6 \%$ and hexane, respectively $(\mathrm{kJ} / \mathrm{kg}$ of solvent). Energy involved to warm liquid to the boiling temperature (or to cool liquid to the demixing temperature) was neglected in this energy consumption estimation because industrially they can be recovered from heat exchangers used to cool (or warm) the miscella. This calculus demonstrates that energy required to evaporate ethanol from heavy phase is around 0.12 times that one required to evaporate hexane in traditional solvent extraction. Despite this energy saving, the extraction process using ethanol will remain more expensive than hexane extraction because of the marc desolventizing step: theoretically, vaporization energy of ethanol is $\frac{\Delta H_{E t O H}}{\Delta H_{H e x}}=2.92$ times higher than hexane. However, high cost of process using ethanol could be compensated by a higher recovery value of products (oil and meal) than actual products: hexane-free products and protein-rich meal.

\subsubsection{Lipid composition}

Figure 6 illustrates the composition of lipids in initial miscella, supernatant and heavy phase, separated by cooling at different temperatures. For convenience, the values are

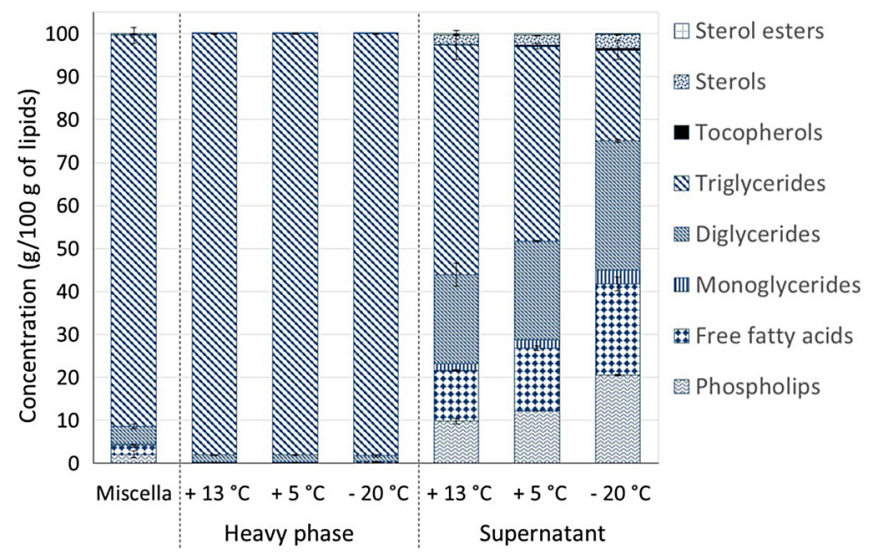

Fig. 6. Lipid composition of extracted oil in the initial miscella or in the cooled and separated phases depending on the cooling temperature. The error bars represent the standard deviation. 
Table 2. Lipid composition of oils from initial miscella and phases separated at three cooling temperatures (in mg/g of lipids).

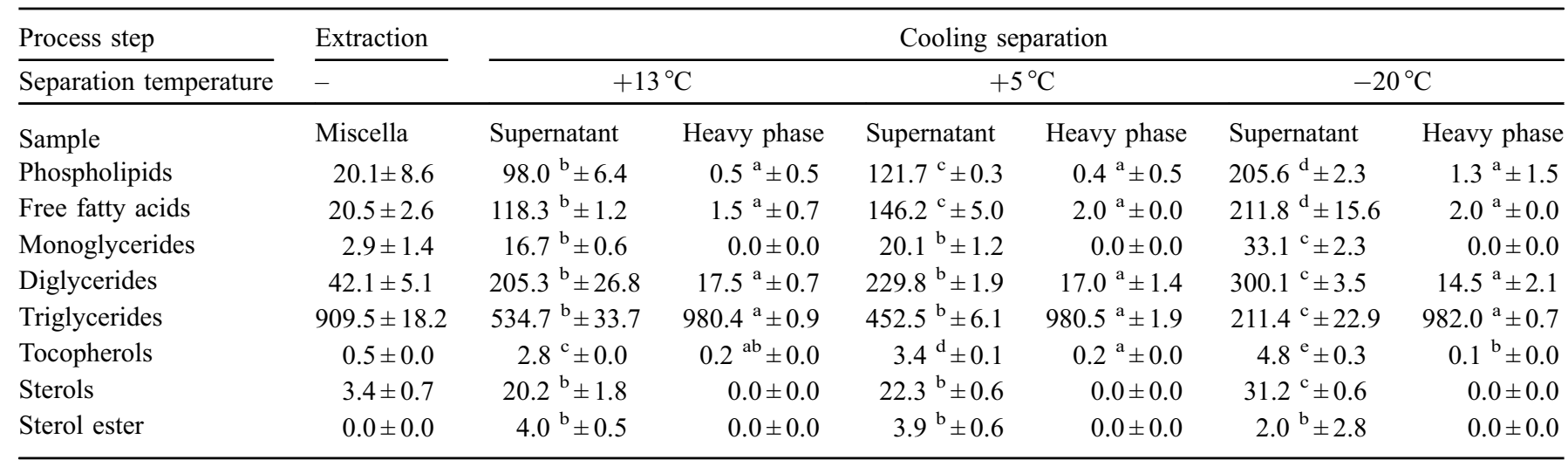

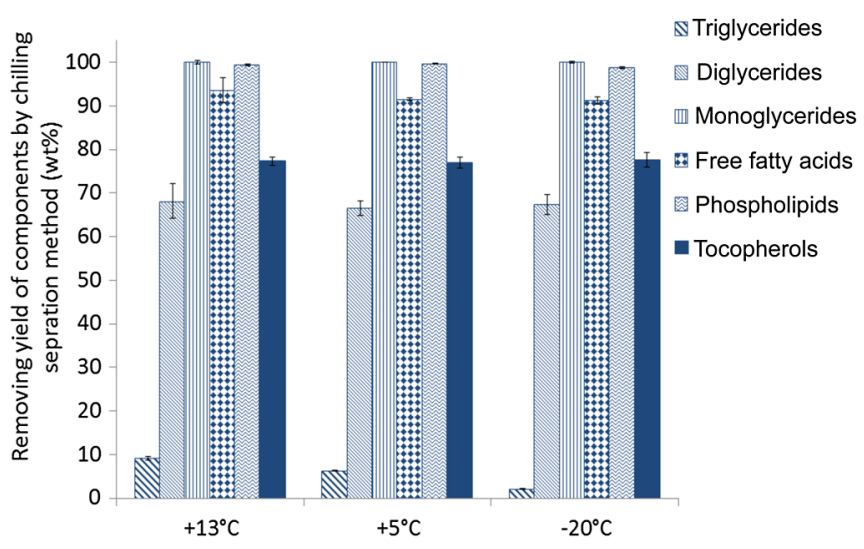

Fig. 7. Influence of the cooling temperature on the proportion of components removed from the decanted oil (in wt.\% compared with extracted component) (Eq. (4)). The error bars represent the standard deviation; ' $\mathrm{a}, \mathrm{b}, \mathrm{c}$ ' indicate a difference at $p<0.05$.

presented in Table 2. Oil extracted by ethanol from rapeseed contained mainly triglycerides $(910 \pm 18 \mathrm{mg} / \mathrm{g}$ of lipids), diglycerides $(42 \pm 5 \mathrm{mg} / \mathrm{g}$ of lipids), free fatty acids $(21 \pm 3 \mathrm{mg} / \mathrm{g}$ of lipids), and phospholipids $(21 \pm 9 \mathrm{mg} / \mathrm{g}$ of lipids). Lipids recovered in the heavy oil-rich phase contained $981 \pm 2 \mathrm{mg}$ of triglycerides and $16 \pm 1 \mathrm{mg}$ of diglycerides per $100 \mathrm{~g}$ of lipids with no significant difference between the cooling temperatures (Fig. 6).

Figure 7 presents the quantity of components removed from the heavy phase after cold separation compared with its total quantity in the extracted miscella (Eq. (4)). As seen in Figure 7, the cooling separation resulted in removal from the oil of the heavy phase of around $91-94 \%$ of free fatty acids, $100 \%$ of monoglycerides, $66-68 \%$ of diglycerides, $99 \%$ of phospholipids, and $77-78 \%$ of tocopherols (with no significant difference between the cooling temperatures). These components were retained in the solvent-rich phase (Fig. 6). The decrease in the cooling temperature significantly increased the quantity of triglycerides recovered in the decanted oil: the decanted yield of triglycerides (compared with the total extracted quantity of triglycerides in initial miscella) ranged from $91 \%$ at $13{ }^{\circ} \mathrm{C}$ to $94 \%$ at $5{ }^{\circ} \mathrm{C}$ and $98 \%$ at $-20^{\circ} \mathrm{C}$. This

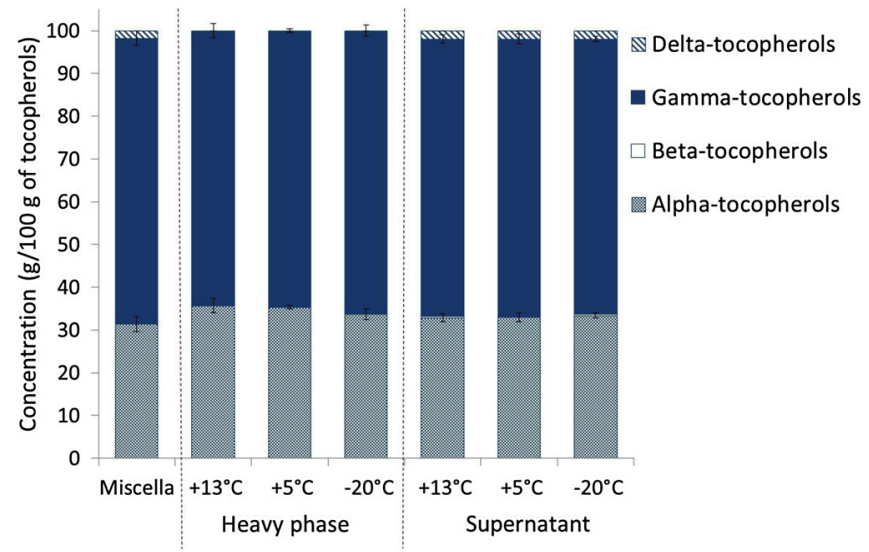

Fig. 8. Composition of extracted tocopherols in the initial miscella or in the cooled and separated phases. The error bars represent the standard deviation.

increase in the percentage of recovered triglycerides in the decanted oil led to a rise in the concentration of the other components (phospholipids, free fatty acids, monoglycerides and diglycerides) in the oil of the solvent-rich phase (Fig. 6).

The change in oil solubility with temperature was accompanied by a partitioning of lipid compounds (and non-lipids) between the oil phase and the solvent phase that can be mainly explained by their different affinities to ethanol. This partitioning had already been observed in earlier studies (Batista et al., 1999; Shiozawa et al., 2015). The liquid-liquid extraction by ethanol has been especially studied as an alternative method of vegetable oil deacidification (Mariano et al., 2011, Rodrigues et al., 2006, Cuevas et al., 2009). These studies were mainly focused on free fatty acid elimination from the oil. However, they also demonstrated the partial removal of some other lipid compounds (Rodrigues et al., 2014).

Tocopherols in the rapeseed oil were mainly composed of alpha-tocopherols $(31 \mathrm{~g} / 100 \mathrm{~g}$ of total tocopherols) and gamma-tocopherols $(67 \mathrm{~g} / 100 \mathrm{~g}$ of total tocopherols). We observed that tocopherols were distributed between the solvent-rich phase and the oil-rich phase, with $77.5 \%$ and $22.5 \%$, respectively (Fig. 7). Figure 8 presents the proportion of the individual tocopherols in each phase. The relative 
M. Citeau et al:: OCL 2018, 25(2), D207

Table 3. Fatty acid composition of oils from initial miscella and phases separated at three cooling temperatures (in relative \%).

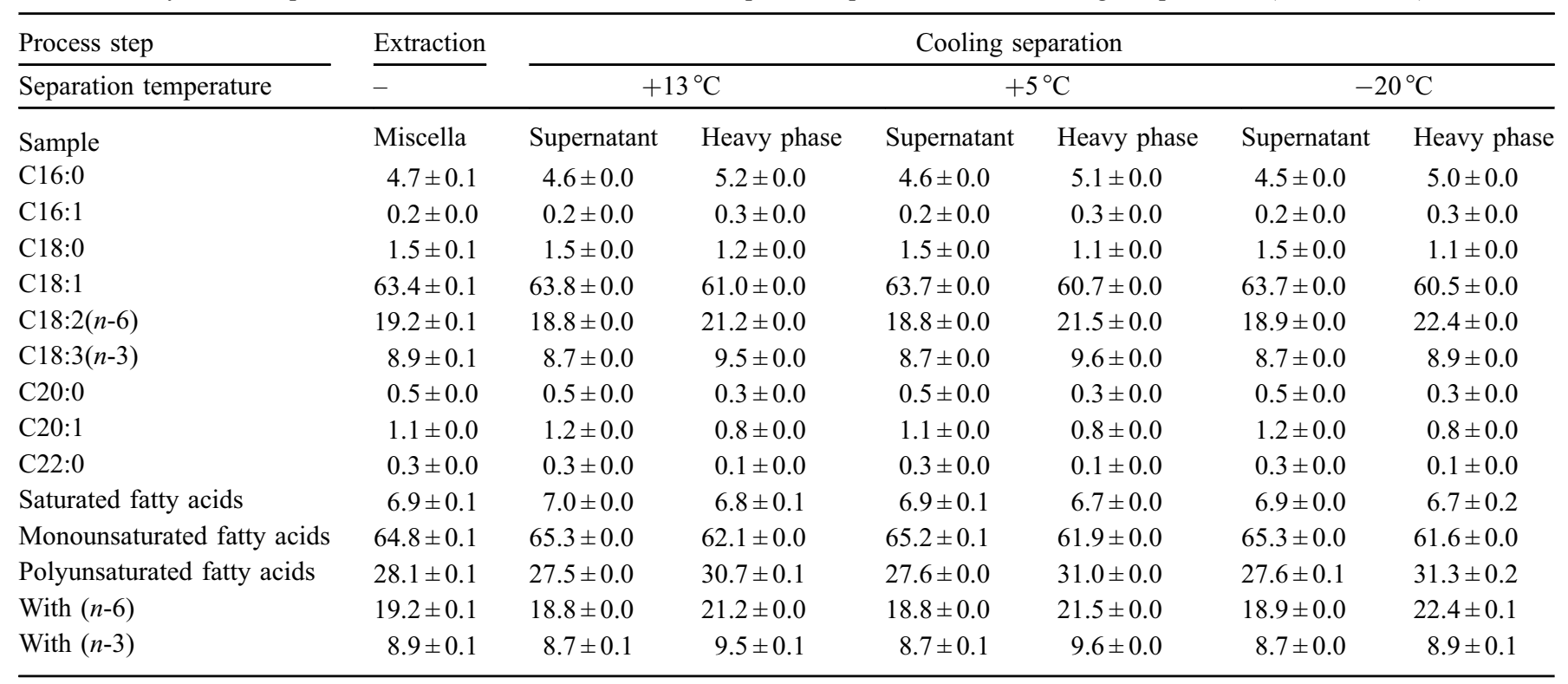

proportion of alpha- and gamma-tocopherols was not differently distributed in each phase compared with the extracted miscella. Furthermore, the composition in tocopherols was not significantly modified by the decrease in temperature in either phase $(p>0.05)$.

\subsubsection{Fatty acid composition}

The fatty acid composition of the decanted oil was similar to that of the total extracted oil (Tab. 3). This observation is in line with the results of Kannan and Gundappa (2014).

However, the decanted oil contained slightly more monosaturated fatty acids than the extracted oil, while the oil remained in the solvent rich-phase showed slightly more polyunsaturated fatty acids than the extracted oil. Gonçalves and Meirelles (2004) observed that the affinity of fatty acids for $94 \%$ ethanol increased with the degree of unsaturation of the carbon chain, consistent with our results.

\section{Conclusion}

Extraction of dried flaked rapeseed kernels with 95.6 wt.\% ethanol at $95^{\circ} \mathrm{C}$ and at a pressure of $340-360 \mathrm{kPa}$ throughout, resulted in practically complete oil extraction after $10 \mathrm{~min}$. The cooling of the obtained miscella $\left(+13\right.$ to $\left.-20^{\circ} \mathrm{C}\right)$ resulted in the formation of two liquid phases: a solvent-rich supernatant and an oil-rich heavy phase.

The cooling induced a partitioning of components between the solvent- and oil-rich phases that was dependent on the cooling temperature: it resulted in preferential concentrating of triglycerides in the heavy phase (91-98\% of extracted triglycerides depending on the cooling temperature) and the removal of extracted undesirable lipid components from the oil of the heavy phase: around $93 \%$ of free fatty acids, $100 \%$ of monoglycerides, $67 \%$ of diglycerides, $99 \%$ of phospholipids and $78 \%$ of tocopherols (with no significant difference between the cooling temperatures).
The results show that the ethanol extraction of rapeseed kernels followed by cooling separation of obtained miscella results in a high quality crude decanted oil (notably free from free fatty acids, phospholipids and non-lipid compounds). This finding suggests a potential simplification of the refining process by elimination of degumming and deacidification steps. In addition, high solvent and low oil concentration in the supernatant (solvent-rich phase) suggests it could be re-used for subsequent kernel extraction with no need for complete solvent distillation.

Acknowledgements. This work was made possible by funds provided by the French Agency for Research (ANR / ALID 13): the authors are grateful for this support. Terres Inovia and SAIPOL were also supporting this project and the authors thank them for both technical and financial contributions.

\section{References}

Abraham G, Hron RJ, Sr., Kuk MS, Wan PJ. 1993. Water accumulation in alcohol extraction of cottonseed. $\mathrm{J} \mathrm{Am} \mathrm{Oil} \mathrm{Chem}$ Soc 70: 207-208.

Allaf T, Fine F, Tomao V, Nguyen C, Ginies C, Chemat F. 2014. Impact of instant controlled pressure drop pre-treatment on solvent extraction of edible oil from rapeseed seeds. OCL 21: A301

Batista E, Monnerat S, Kato K, Stragevitch L, Meirelles AJA. 1999. Liquid-liquid equilibrium for systems of canola oil, oleic acid, and short-chain alcohols. J Chem Eng Data 44: 1360-1364.

Beckel AC, Belter PA, Smith AK. 1948a. The non-distillation alcohol extraction process for soybean oil. J Am Oil Chem Soc 25: 10-12.

Beckel AC, Belter PA, Smith AK. 1948b. Process of extraction from vegetable materials, Patent 2,445, 931.

Berot S, Briffaud J. 1983. Parameters for obtaining concentrates from rapeseed and sunflower meal. Plant Food Hum Nutr 33: 237-242.

Bessa LCBA, Ferreira MC, Rodrigues CEC, Batista EAC, Meirelles AJA. 2017. Simulation and process design of continuous countercurrent ethanolic extraction of rice bran oil. $J$ Food Eng 202: 99-113. 
Carré P. 2012. Recovery of low temperature heat in oil mills. OCL 19: 324-331.

Crank J. 1975. The mathematics of diffusion. Oxford (UK): Clarendon Press.

Cuevas MS, Rodrigues CEC, Meirelles AJA. 2009. Effect of solvent hydration and temperature in the deacidification process of sunflower oil using ethanol. J Food Eng 95: 291-297.

Fauduet H, Coic JP, Lessire M, Quinsac A, Ribaillier D, Rollin P. 1995. Rapeseed meal upgrading-pilot scale preparation of rapeseed meal materials with high or low glucosinolate contents. Anim Feed Sci Tech 56: 99-109.

Fine F, Vian MA, Fabiano Tixier SA, Carré P, Pages X, Chemat F. 2013. Les agro-solvants pour l'extraction des huiles végétales issues de graines oléagineuses. OCL 20: A502.

Folch J, Lees M, Sloane Stanley GH. 1957. A simple method for the isolation and purification of total lipids from animal tissues. $J$ Biol Chem 226: 497-509.

Gonçalves CB, Meirelles AJA. 2004. Liquid-liquid equilibrium data for the system palm oil + fatty Acids + ethanol + water at 318.2 K. Fluid Phase Equilibr 221: 139-150.

Hron RJ, Koltun SP. 1984. An aqueous ethanol extraction process for cottonseed oil. J Am Oil Chem Soc 61: 1457-1460.

Kannan PKP, Gundappa GKA. 2014. Impact of different deacidification methods on quality characteristics and composition of olein and stearin in crude red palm oil. J Oleo Sci 63: 1209-1221.

Kozlowska H, Nowak R, Zadernowski H. 1991. Influence of selected technological processes on improvement of rapeseed meal and flour feed quality. Part I: Influence of thermal treatment and ethanol extraction on chemical composition of rapeseed products. Nahrung 35: 485-489.

Mabona N, Muzenda E, Mollagee M, Mguni LL. 2014. Nondistillation oil extraction from SCG using ethanol and propan-2ol. IJRCMECE 1: 119-123.

Mariano RGB, da Silva CM, Couri S, Nogueira RI, Freitas SP. 2011. Partition of free fatty acids in deacidification of macaúba pulp oil by liquid-liquid extraction using ethanol/water as solvent. Defect Diffus Forum 312-315: 554-559.

Mordret F. 1992. Détermination de la constitution. In: Technique et Documentation, ed. Manuel des corps gras. Tome 2. Pari (France): Lavoisier.

NIST, National Institute of Standards and Technology, U.S. Department of Commerce. Available from http://webbook.nist. gov/ (last consult: 2017/09/20).
Perrier A, Delsart C, Boussetta N, Grimi N, Citeau M, Vorobiev E. 2017. Effect of ultrasound and green solvents addition on the oil extraction efficiency from rapeseed flakes. Ultrason Sonochem 39: 58-65.

Rao RK, Arnold LK. 1956. Alcoholic extraction of vegetable oils: III Solubilities of babassu, coconut, olive, palm, rapeseed and sunflower seed oils in aqueous ethanol. J Am Oil Chem Soc 33: 389-391.

Rittner H. 1992. Extraction of vegetable oils with ethyl alcohol. Oléagineux 47: 29-42.

Rodrigues CEC, Oliveira R. 2010. Response surface methodology applied to the analysis of rice bran oil extraction process with ethanol. Int J Food Sci Tech 45: 813-820.

Rodrigues CEC, Onoyama MM, Meirelles AJA, 2006. Optimization of the rice bran oil deacidification process by liquid-liquid extraction. J Food Eng 73: 370-378.

Rodrigues CEC, Gonçalves CB, Marcon EC, Batista EAC, Meirelles AJA. 2014. Deacidification of rice bran oil by liquid-liquid extraction using a renewable solvent. Sep Purif Technol 132: 84-92.

Sawada MM, Venâncio LL, Toda TA, Rodrigues CEC. 2014. Effects of different alcoholic extraction conditions on soybean oil yield, fatty acid composition and protein solubility of defatted meal. Food Res Int 62: 662-670.

Shiozawa S, Bessa LCBA. Ferreira MC, Meirelles JA, Batista EAC. 2015. Liquid-liquid equilibrium data for fatty systems containing monoacylglycerols and diacylglycerols. J Chem Eng Data 60: 2371-2379.

Sicaire AG, Abert Vian M, Fine F, Carré P, Tostain S, Chemat F. 2015a. Experimental approach versus COSMO-RS assisted solvent screening for predicting the solubility of rapeseed oil. OCL 22: D404.

Sicaire AG, Vian M, Fine F, et al. 2015b. Alternative bio-based solvents for extraction of fat and oils: solubility prediction, global yield, extraction kinetics, chemical composition and cost of manufacturing. Int J Mol Sci 16: 8430-8453.

Toda TA, Sawada MM, Rodrigues CEC. 2016. Kinetics of soybean oil extraction using ethanol as solvent: Experimental data and modelling. Food Bioprod Process 98: 1-10.

Zhang H, Liu D. 2007. The reseach on the double low rapeseed protein concentrated by a new preparation method and its functional properties, 12th IRC, Wuhan China 2007 Vol 5: GCIRC, Quality, Nutrition And Processing: Processing Technology.

Cite this article as: Citeau M, Albe Slabi S, Joffre F, Carré P. 2018. Improved rapeseed oil extraction yield and quality via cold separation of ethanol miscella. OCL 25(2): D207. 